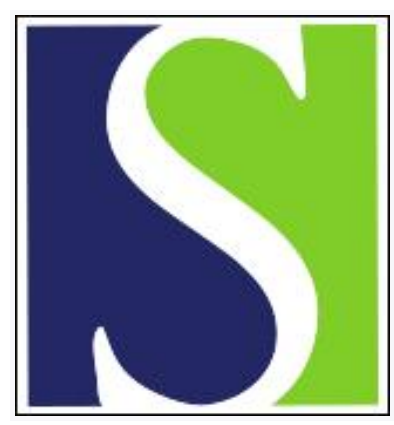

Scand J Work Environ Health 1979;5(2):109-114

https://doi.org/10.5271/sjweh.2662

Issue date: Jun 1979

Ten-year coronary mortality of workers exposed to carbon disulfide.

by Tolonen M, Nurminen M, Hernberg S

The following article refers to this text: 1989;15(4):245-264

Key terms: carbon disulfide; cohort study; coronary heart disease; coronary mortality; exposure; mortality; worker

This article in PubMed: www.ncbi.nlm.nih.gov/pubmed/472681

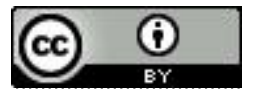




\title{
Ten-year coronary mortality of workers exposed to carbon disulfide
}

\author{
by MATTI TOLONEN, M.D., ${ }^{1}$ MARKKU NURMINEN, L.Sc.," and \\ SVEN HERNBERG, M.D."
}

\begin{abstract}
TOLONEN, M., NURMINEN, M. and HERNBERG, S. Ten-year coronary mortality of workers exposed to carbon disulfide. Scand. $j$. work environ. \& health 5 (1979) 109-114. Two cohorts, one comprising 343 viscose rayon workers exposed for at least five years to carbon disulfide $\left(\mathrm{CS}_{*}\right)$ and the other made up of 343 nonexposed men, were followed from 1967 to 1977 with respect to coronary heart disease (CHD) mortality. In the examination in 1967 known risk factors of CHD were controlled; only blood pressure was slightly higher in the exposed group. The difference was considered a result of exposure. Five exposed and eight nonexposed men had experienced a previous clinical myocardial infarction. The total mortality was $48(14 \%$ ) in the exposed group and $31(9 \%)$ in the compeer group $(\mathrm{p}-0.05) ; 29$ exposed and 11 nonexposed men had died from CHD $(\mathrm{p}<0.01)$, and 5 exposed and 1 nonexposed from other cardiovascular causes $(\mathrm{p}=0.1)$. All coronary deaths occurred in the age interval 40 to 69 years. The estimated risk of death from CHD for this 30-year age span, assuming no competing risks of death, was $31.9 \%$ for the exposed cohort against $13.3 \%$ for the compeers. A multivariate analysis yielded age, raised blood pressure, and exposure to $\mathrm{CS}_{2} .2$ as prominent risk factors. The contributory risk caused by past occupational CS. exposure seemed to increase the already notoriously high risk of $\mathrm{CHD}$ mortality among Finnish men.
\end{abstract}

Key words: carbon disulfide, cohort study, coronary heart disease.

A prospective study of mortality from coronary heart disease (CHD) among viscose rayon workers exposed to carbon disulfide $\left(\mathrm{CS}_{.}\right)$) has been in progress since 1967. Five- and eight-year mortality statistics have already been published (2, 4, 8). In the present paper we report the results of the ten-year follow-up.

1 Uusimaa Regional Institute of Occupational Health, Helsinki, Finland.

- Department of Epidemiology and Biometry, Institute of Occupational Health, Helsinki, Finland.

Reprint requests to: Dr. Matti Tolonen, Uusimaa Regional Institute of Occupational Health, Arinatie 3, SF-00370 Helsinki 37, Finland.

\section{MATERIAL AND METHODS}

Two cohorts of 343 men each, one exposed to $\mathrm{CS}_{2}$ and the other nonexposed, were set up in 1967 (3). The exposed group comprised men from a Finnish viscose rayon plant founded in 1942. All of this group had been working for at least five years between 1942 and 1967 in departments where they were exposed to CS. The mean concentrations of $\mathrm{CS}_{2}+\mathrm{H}_{2} \mathrm{~S}$ (hydrogen sulfide) were probably very high in the $1940 \mathrm{~s}$, about 20 to $40 \mathrm{ppm}$ in the $1950 \mathrm{~s}$, and about 10 to $30 \mathrm{ppm}$ in the 1960 s. In 1967, at the time of selection into the study, the age of the exposed persons ranged from 24 to 64 years with a 
mean of 45 years. The compeer group was selected from male employees of a paper mill company situated in the same town. These men had no history of occupational exposure to any specific toxic agent. They were selected so as to match the exposed workers individually with respect to age, district of birth, and similarity of work (blue or white collar).

Smoking habits and leisure-time physical activity were checked; and physical fitness, obesity, blood lipids, glucose tolerance, and exercise electrocardiography were examined during the set-up phase of the study. No important differences were found between the two groups (3). These examinations were repeated at the fiveyear follow-up examination, and, again, no relevant significant differences were found. However, the diastolic and systolic blood pressures and the frequency of reported chest pain were higher among the exposed men at both examinations (8).

Readers interested in details of the original study design, examination methodology, and the toxic environment of the viscose rayon plant are referred to previous papers on this project $(2,3,4,8)$.

In this present report the exposure to $\mathrm{CS}_{\text {. }}$ during the follow-up period 19721977 has not been analyzed since exposure had ceased for some members of the exposed group because of death, illness or disability. In addition the plant management had made an active effort to transfer men with a long exposure history to noncontaminated departments. In 1972 only half of the original exposed cohort was still exposed, and three years later there was less than $20 \%$ of this same group still working in departments with exposure to $\mathrm{CS}_{2}$ (4). Moreover, the work conditions had improved with time, and consequently the exposure levels even for those still exposed had decreased considerably (9). Since 1967 the production of $\mathrm{CS}_{2}$ has been stopped, the viscose film factory has been sold to another company, and the ventilation system of the plant has been renewed.

The survival status of both cohorts could be checked without any failure. The death certificates were collected at the Central Statistical Office of Finland and the reported causes of death (11) were used for the mortality analysis.

\section{RESULTS}

Fourteen percent of the exposed and $9 \%$ of the compeer cohort had died during the ten-year period (table 1). The difference in total mortality rates was on the verge of statistical significance $(p \simeq 5 \%)$, whereas coronary deaths (11) were over 2.5 times more frequent among the exposed group, the difference being statistically significant $(p<1 \%$ \%). Other cardiovascular deaths occurred 5 to 1 in ex-

Table 1. Mortality data from the ten-year follow-up.

\begin{tabular}{lccc}
\hline Group & $\begin{array}{c}\text { Coronary heart } \\
\text { disease deaths }\end{array}$ & $\begin{array}{c}\text { Other cardio- } \\
\text { vascular deaths }\end{array}$ & $\begin{array}{c}\text { All } \\
\text { deaths }\end{array}$ \\
\cline { 2 - 4 } Exposed $(\mathrm{N}=343)$ & 29 & 5 & 48 \\
Nonexposed $(\mathrm{N}=343)$ & 11 & 1 & 31 \\
\hline Mortality ratio a & 2.64 & 5.00 & 1.55 \\
$95 \%$ confidence interval b & $1.34-5.19$ & $0.59-42.6$ & $1.01-2.37$ \\
$\chi^{2}(1)$ c & 8.10 & 2.66 & 3.66 \\
p-value & 0.0044 & 0.102 & 0.056 \\
\hline
\end{tabular}

a Calculated with "count denominators."

b The logarithm of the mortality ratio is assumed to be approximately normally distributed (5).

c An asymptotically chi-squared test statistic with binomial expectation and variance. 
Table 2. Quinquennial mortality data for coronary heart disease. ${ }^{a}$

\begin{tabular}{|c|c|c|}
\hline Group & July 1967 - June 1972 & July $1972-$ June 1977 \\
\hline Exposed $(\mathrm{N}=343)$ & 14 & 15 \\
\hline Nonexposed $(\mathrm{N}=343)$ & 3 & 8 \\
\hline Rate ratio & 4.67 & 1.94 \\
\hline \multicolumn{3}{|l|}{$95 \%$ confidence } \\
\hline interval & $1.35-16.1$ & $0.83-4.51$ \\
\hline$\chi^{2}(1)$ & 7.12 & 2.37 \\
\hline p-value & 0.0076 & 0.12 \\
\hline
\end{tabular}

a See the footnotes to table 1 .

Table 3. Age-specific mortality rates for coronary heart disease (CHD).

\begin{tabular}{|c|c|c|c|}
\hline $\begin{array}{l}\text { Age group } \\
\text { (years) }\end{array}$ & CHD deaths & Follow-up years & $\begin{array}{l}\text { Mortality rate } \\
\text { per } 1,000 \text { years }\end{array}$ \\
\hline
\end{tabular}

\section{Exposed cohort}

$\begin{array}{rrrrrr}25-39 & - & 480 & 0 & \\ 40-44 & 1 & 587 & 1.7 & 3.2 \\ 45-49 & 3 & 680 & 4.4 & \\ 50-54 & 5 & 541 & 9.2 & 12.8 \\ 55-59 & 8 & 479 & 16.7 & \\ 60-64 & 8 & 356 & 22.5 & 23.4 \\ 65-69 & 4 & 157 & 25.5 & \\ 70-74 & - & 36 & 0 & \\ 25-74 & 29 & 3,316 & 8.8 & \\ 40-69 & 29 & 2,800 & 10.4\end{array}$

Nonexposed cohort

\begin{tabular}{lrrrrl}
$25-39$ & - & 515 & 0 & \\
$40-44$ & - & 565 & 0 & 1.7 \\
$45-49$ & 2 & 641 & 3.1 & 1.8 & \\
$50-54$ & 1 & 559 & 7.8 & 4.7 \\
$55-59$ & 4 & 512 & 5.0 & \\
$60-64$ & 2 & 186 & 10.8 & 6.8 \\
$65-69$ & 2 & 28 & 0 & \\
$70-74$ & - & 3,408 & 3.2 & \\
$25-74$ & 11 & 2,852 & 3.9 & \\
$40-69$ & 11 & & \\
\hline
\end{tabular}

cess in the exposed group, but the difference did not attain the level of statistical significance.

When the mortality data for CHD was divided into two successive five-year periods (table 2), the point estimate of the mortality rate ratio declined from the highly significant value of 4.7 during the first five-year period to a nonsignificant 1.9 during the second quinquennial interval.
In the preceding tabulation, we treated all cases globally and made no reference to age. The age-specific mortality rates for $\mathrm{CHD}$ are given in table 3 . The rates are expressed as cases per 1,000 personyears. Because of the small number of CHD deaths, particularly in the five-year age strata of the compeer population, the point estimates of the mortality rates show statistical fluctuations. The estimated relative coronary death rates (exposed vs. 
nonexposed) for the ten-year age intervals 40 to 49,50 to 59 , and 60 to 69 were 1.9 , 2.7 , and 3.4, respectively. For the entire age interval, 40 to 69 years, the corresponding rate was 2.71 (95\% confidence interval 2.65-2.77).

The follow-up experience of both cohorts has been summarized by the com-

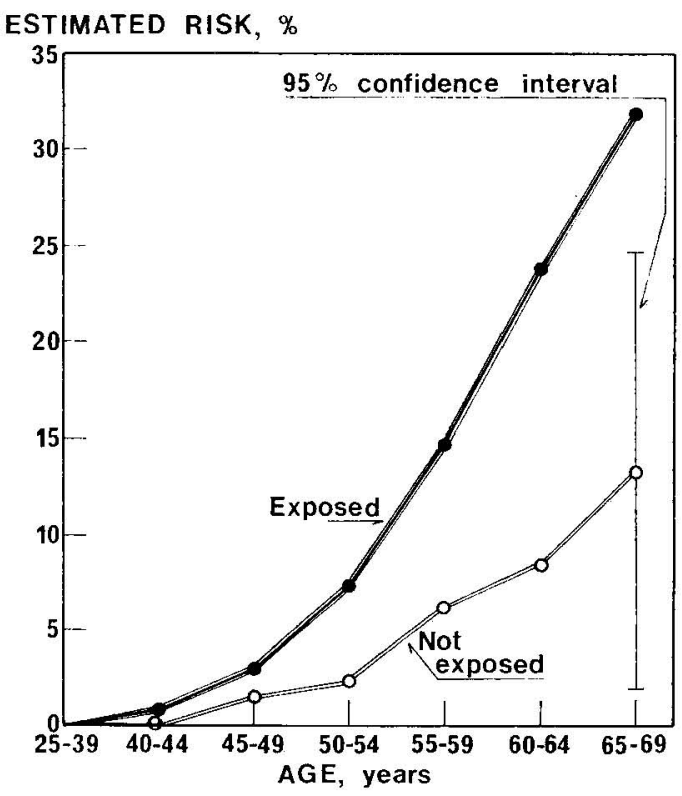

Fig. 1. Estimated risk of death from coronary heart disease (estimated by assuming that the distribution of deaths is uniform or equivalent, i.e., that the survivor(ship) function is linear, within the five-year age intervals). putation of their estimated (attrition) probabilities of death from CHD (fig. 1) (12). Thus, e.g., for a nonexposed 45-year-old person, the 20-year risk of dying from $\mathrm{CHD}$, assuming no competing risks from other diseases, is computed as (1):

$$
\underset{i \mathrm{i}=45-49}{I I^{(31)-6 i 4}\left(1-\mathrm{M}_{\mathrm{i}}\right)}=8.5 \%
$$

where $\mathrm{M}_{\mathrm{i}}$ stands for the Frost estimate of death rate in the $i$ th age interval. The estimation was based on the assumption that deaths occur uniformly throughout the five-year age intervals. For the age span 40 to 69 years the death risk from CHD among the exposed persons was 31.9 ( \pm 4.3$) \quad \%$ against $13.3( \pm 5.8) \quad \%$ among the nonexposed.

We also studied whether the effect of $\mathrm{CS}_{2}$ exposure and other coronary risk factors could be quantitated. The other risk factors considered, quantitated and included in the multivariate analysis were serum cholesterol level, diastolic blood pressure, cigarette consumption, and age (all measured at the beginning of the follow-up).

The linear discriminant function yielded an individual contribution to CHD risk for each of these factors, but the analysis did not accurately predict future CHD deaths. Nevertheless age, CS., exposure, and blood. pressure stood out as prominent.

Table 4. Coronary heart disease (CHD) mortality among cohort members with previous nonfatal

\begin{tabular}{|c|c|c|c|c|c|c|c|}
\hline \multirow[b]{3}{*}{ Group } & \multicolumn{6}{|c|}{ Previous nonfatal infarction or diabetes } & \multirow{3}{*}{$\begin{array}{c}\text { Total } \\
\frac{\mathrm{d}_{1}+\mathrm{d}_{2}}{\mathrm{n}_{1}+\mathrm{n}_{\underline{y}}} \% / 0\end{array}$} \\
\hline & \multicolumn{3}{|c|}{ Yes } & \multicolumn{3}{|c|}{ No } & \\
\hline & $\begin{array}{c}\text { CHD } \\
\text { deaths } \\
\left(d_{1}\right)\end{array}$ & $\begin{array}{l}\text { Sub- } \\
\text { group } \\
\text { size } \\
\left(\mathrm{n}_{1}\right)\end{array}$ & $\frac{d_{1}}{n_{1}} \%$ & $\begin{array}{c}\text { CHD } \\
\text { deaths } \\
\left(d_{\nu}\right)\end{array}$ & $\begin{array}{l}\text { Sub- } \\
\text { group } \\
\text { size } \\
(\mathrm{n} .)\end{array}$ & 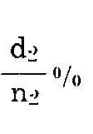 & \\
\hline Exposed $(\mathrm{N}=343)$ & 4 & 6 & 66.7 & 25 & 337 & 7.4 & 8.5 \\
\hline Nonexposed $(\mathrm{N}=343)$ & 3 & 14 & 21.4 & 8 & 329 & 2.4 & 3.2 \\
\hline Exposed/nonexposed & & & 3.1 & & & 3.1 & 2.6 \\
\hline
\end{tabular}
myocardial infarction or diabetes mellitus. 


\section{DISCUSSION}

An excess of coronary deaths occurred in the exposed cohort during the ten-year period of the follow-up. This observation is congruent with other mortality studies from England (7), Norway (6) and the United States (Mancuso, unpublished results). In addition we are aware of a Dutch study (10) which did not show any excess mortality; however, because of too short a follow-up and too restricted a cohort size, this seemingly negative result must be considered noninformative.

Ideally, at the beginning of follow-up, both the exposed and the nonexposed cohorts should be free from the disease under study. Neither should exposure start before the start of the follow-up if previous effects in the exposed group are to be excluded. Our prospective follow-up was, however, an extension of a retrospective follow-up study (2), and a minimum exposure history of five years had been required for the members of the exposed cohort in order to increase efficiency. Neither were the cohorts preselected in 1967 with regard to CHD. The examination of the groups selected revealed later that five exposed and eight nonexposed persons had previously suffered a myocardial infarction. Diabetes is also associated with CHD, and there were one exposed and six nonexposed persons with diabetes diagnosed up until 1967. Thus altogether there were 20 men with one of the two diseases, i.e., CHD or diabetes, at the start of the follow-up. Since $70 \%$ of them belonged to the nonexposed group (table 4), the result of the follow-up, i.e., excess coronary mortality in the exposed cohort, can by no means be attributed to selection into the study.

The CHD fatality rate was $35 \%$ for those with either disease and only $5 \%$ for those without either disease. But in both subgroups the fatality ratio, i.e., deaths from CHD among the exposed vs. the nonexposed, was the same, namely, 3 . Thus, in relative terms, the presence of these two diseases did not produce a differential bias (different biases between the compared series) in the estimates obtained for CHD mortality in tables 1 and 2 .

The many parameters recorded at the start of the prospective study should ideally represent the base-line characteristics of the cohorts. However, blood pressure was higher among the exposed persons; these persons also reported chest pain more frequently than the nonexposed ones. Both of these observations were considered to result from $\mathrm{CS}_{2}$ exposure (8). No other significant differences could be found between the groups with respect to coronary risk factors.

The mortality rates were treated in two quinquennial periods so that a comparison of the previously published $(2,4,8)$ and the latest data would be possible. Expectedly, the number of CHD deaths had increased in the compeer group (from three between 1967 and 1972 to eight between 1972 and $\left.1977^{3}\right)$; yet the exposed cohort experienced no marked increase (14 and 15 for the two time spans, respectively). The role of chance is displayed in a scrutinization of annual CHD mortality during the last quinquennial period. In 1973, 1974, and 1975 six CHD deaths had occurred in both groups (4), but during the last two years (1976 and 1977) nine CHD deaths had occurred among the exposed workers against two among the compeers. The future trend of the rate ratio remains unpredictable.

The estimated multivariate risk model function showed poor discriminating power, probably for the following reasons: (a) The exposure variable was a multiplicative index of time and intensity; this approximate measure of personal exposure did not account for the potential separate effects of these two components. (b) It was impossible to update the index for the ten years of follow-up - it thus referred to past exposure only. (c) The compared groups were not entirely free from CHD in 1967. (d) Already in 1967 the groups differed with respect to blood pressure. (e) Missing measurements (32 cholesterol values) were replaced by group mean values. (f) No interaction term could be included in the model function because of the limiting size of the smaller group of cases $(N=40)$. An attempt was made to employ another model form (the complementary log-log transformation of the

$\therefore$ The follow-up started on 1 July 1967, hence the overlapping of years. 
risk parameter), but the computational difficulties involved proved to be too great.

The difference in cumulative incidences (fig. 1) clearly depicts the excess coronary mortality risk caused by exposure to $\mathrm{CS}_{\mathrm{i}}$. Throughout the world Finnish men notoriously have the highest risk for CHD. Consequently an additional risk factor of occupational $\mathrm{CS}_{2}$ exposure may result in higher mortality rates among Finns than among other populations.

\section{REFERENCES}

1. CHIANG, C. L. Introduction to stochastic processes in biostatistics. John Wiley, New York, NY 1968. $313 \mathrm{p}$.

2. HERNBERG, S., NURMINEN, M. and TOLONEN, M. Excess mortality from coronary heart disease in viscose rayon workers exposed to carbon disulfide. Work environ. health 10 (1973) 93-99.

3. HERNBERG, S., PARTANEN, T., NORDMAN, C.-H. and SUMARI, P. Coronary heart disease among workers exposed to carbon disulphide $B r . j$. ind. med. 27 (1970) $313-325$.

4. HERNBERG, S., TOLONEN, M. and NURMINEN, M. Eight-year follow-up of viscose rayon workers exposed to carbon disulfide. Scand. j. work environ. \& health 2 (1976) 27-30.

5. KATZ, D., BABTISTA, J., AZEN, S. and PIKE, M. Obtaining confidence intervals for the risk ratio in cohort studies. Biometrics 34 (1978) $469-474$.

6. MOVÉ, G. Coronary heart disease and occupational exposure to carbon disulfide. In: D. DJURIC, L. GRAOVAC-LEPOSAVIC, A. POSTIC-GRUJIN and M. STANKOVIC (eds.), Abstract, II international symposium on toxicology of carbon disulfide. Institute of Occupational and Radiological Health, Beograd 1971.

7. TILLER, J. R., SCHILLING, R. S. F. and MORRIS, J. N. Occupational toxic factor in mortality from coronary heart disease. Br. med. j. 4 (1968) 407-411.

8. TOLONEN, M., HERNBERG, S., NURMINEN, M. and TIITOLA, K. A follow-up study of coronary heart disease in viscose rayon workers exposed to carbon disulfide. Br. j. ind. med. 32 (1975) $1-10$.

9. TUSA, L. Procedures adopted for diminution of deleterious effects of carbon disulphide in Kemira Oy Säteri's factories. In: M. TOLONEN (ed.), The IV international symposium on occupational health in the production of artificial fibres, $A b-$ stracts. Institute of Occupational Health, Helsinki 1977, p. 35.

10. VERTIN, P. G. Incidence of "cardiovascular disease in the Dutch viscose rayon industry. J. occup med. 20 (1978) 346-350.

11. WORLD HEALTH ORGANIZATION. World health statistical annual 1967: Vital statistics and causes of death (vol. 1). Geneva $1970.783 \mathrm{p}$.

12. WUNSCH, G. and TERMOTE, M. Introduction to demographic analysis: Principles and methods. Plenum Press, New York, NY 1978, pp. 24-26. 